\title{
Hydroacoustic Assessment of Abundance and Diel Distribution of Sockeye Salmon and Kokanee in the Sawtooth Valley Lakes, Idaho
}

\author{
David A. Beauchamp \\ Utah Cooperative Fish and Wildlife Research Unit ${ }^{1}$ \\ Department of Fisheries and Wildlife-Ecology Center \\ Utah State University, Logan, Utah 84322-5210, USA
}

\author{
Chris Luecke, Wayne A. Wurtsbaugh, Howard G. Gross, ${ }^{2}$ and \\ PHAEdRA E. Budy \\ Department of Fisheries and Wildlife-Ecology Center \\ Utah State University, Logan, Utah 84322-5210, USA
}

ScotT SPAULding

Shoshone-Bannock Indian Fisheries Department

Post Office Box 306, Fort Hall, Idaho 83203, USA

ROBERT Dillenger

Idaho Department of Fish and Game

1798 Trout Road, Eagle, Idaho 83616, USA

\author{
Chad P. Gubala \\ Institute for Natural Systems Engineering, Department of Civil and Environmental Engineering \\ Utah State University, Logan, Utah 84322-4110, USA
}

\begin{abstract}
We used dual-beam hydroacoustics and echo integration techniques, combined with midwater trawling and gillnetting, to assess the abundance and distribution of the endangered Snake River juvenile sockeye salmon and resident kokanee (both Oncorhynchus nerka) in Sawtooth Valley lakes of Idaho during September 1991 and 1992. Abundance of $O$. nerka varied among the four lakes containing this species $(12,500-257,000)$ and varied between years in Redfish Lake (86,400 in 1994 and 241,000 in 1992) and Alturas Lake (230,000 in 1991 and 257,000 in 1992). In Alturas Lake, where piscivore densities were high and zooplankton densities were low, small acoustic targets ( $\leq 18 \mathrm{~cm}$ long) were nearly absent from the limnetic zone during daylight, and high densities remained in colder intermediate depths $(15-30 \mathrm{~m})$ during crepuscular and nocturnal periods. In Redfish Lake, where predator density was much lower and zooplankton density was higher, targets concentrated in schools at $25-30 \mathrm{~m}$ during daylight, dispersed into the upper $10 \mathrm{~m}$ at dusk, then were broadly distributed over the upper $30 \mathrm{~m}$ at night. In Pettit and Stanley lakes, nocturnal distributions of smaller $(3-7 \mathrm{~cm})$ and intermediate $(7-18 \mathrm{~cm})$ target sizes were skewed toward the epilimnion, and larger targets remained in the metalimnion or upper hypolimnion. The different diel vertical distribution patterns suggested that juvenile $O$. nerka exposed to limited food and high predation risk consumed smaller rations and maximized bioenergetic efficiency. Populations with higher food supplies and exposed to lower piscivore densities exploited the higher epilimnetic prey densities and temperatures at night and crepuscular periods to maximize growth but deviated further from bioenergetic efficiency. Populations responded differently to the unique combination of constraints that limit potential sockeye salmon smolt production at each lake. Consequently, different management strategies may be needed in each lake.
\end{abstract}

The abundance and temporal-spatial distribution of organisms in limnetic environments determine

\footnotetext{
${ }^{1}$ The Unit is jointly supported by the U.S. Geological Survey, Utah State University, Utah Division of Wildlife Resources, and the Wildlife Management Institute.

${ }^{2}$ Present address: SWCA Inc., Environmental Consultants, 56 West 400 South, Suite 201, Salt Lake City, Utah 84101, USA.
}

their exposure to important environmental conditions (e.g., temperature, light, dissolved oxygen), localized food supplies (Brandt et al. 1992), and predators (Clark and Levy 1988; Levy 1990; Walters and Juanes 1993; Beauchamp 1994). The abundance or density of different sizes and species distributed within this spatial-temporal pattern influences the magnitude of competitive and predatory interactions. 
Processes most likely to limit production of juvenile sockeye salmon Oncorhynchus nerka in nursery lakes include food supply and predation (Clark and Levy 1988; Burgner 1992; Walters and Juanes 1993; Beauchamp et al. 1995). Per capita food supply is a function of lake productivity, access to regions of high prey density, and density of interspecific and intraspecific competitors. Direct effects of predation depend on the number of juvenile sockeye salmon eaten relative to their abundance in the lake. Predators can also indirectly affect production of juvenile sockeye salmon by limiting access to food-rich areas. Eggers (1978) and Clark and Levy (1988) hypothesized that juvenile sockeye salmon performed diel vertical migrations to feed in relatively shallow, zooplankton-rich strata while minimizing exposure to visually feeding piscivores. Juvenile sockeye salmon often feed only during crepuscular periods (Doble and Eggers 1978; Eggers 1978; Levy 1990); consequently daily ration and growth may be considerably lower for crepuscular feeders than for fish feeding throughout daylight and twilight hours. Because survival is related to body size (Miller et al. 1988), density and distribution represent important links between growth of individuals and dynamics of the population.

Organisms should recognize and adjust to gradients of food supply, temperature, and predation risk to optimize growth and survival and to maximize overall fitness. To date, no field study has directly related the behavioral and physiological responses of juvenile sockeye salmon to observed gradients of predation risk and food supply. By comparing diel vertical distribution patterns of closely related $O$. nerka populations (including both anadromous sockeye salmon and the resident kokanee) near the end of the growing season, we had the opportunity to examine how similar stocks responded to different combinations of food supply and predation risk in a variable thermal and photic environment. The results of these strategies could be measured as body size after the first growing season. Moreover, from the diel distribution patterns, we can gain insight into whether the priorities are to maximize energy acquisition, maximize efficient energy transfer, minimize predation risk, or to optimize the tradeoff between some or all of these constraints. Such an examination alerts managers to the hierarchy of limitations that must be overcome in specific lakes before low-density populations can recover.

The Snake River strain of sockeye salmon was listed as a federally endangered stock in 1991 due to precipitous declines in adult returns (Bevan et al. 1994). This strain exhibits unique life history attributes that represent extremes for the anadromous form of this species, including the longest upstream migration $(1,450 \mathrm{~km})$, highest elevation of spawning and rearing habitat $(1,996 \mathrm{~m}$ above mean sea level), and the southernmost extent of the species' range. Spawning and freshwater rearing of this stock occurs in the Sawtooth Valley lakes, Idaho. Spawning escapement into the basin has ranged from 1 to 4,361 spawners during the years that have been monitored between 1954 and the present (Bjornn et al. 1968; Warren 1988; J. A. Hall-Griswold and T. Cochnauer, Idaho Department of Fish and Game, unpublished data). Factors recognized as contributing to the decline of this stock include irrigation diversions, hydroelectric dams, other types of habitat degradation, and incidental harvest in fisheries. These factors affect survival of migratory juvenile and adult fish but do not address potential limitations during the freshwater incubation and rearing stages. Because this population produces an average of $2,430 \mathrm{eggs} /$ female (Warren 1988) and because egg-to-smolt survival can vary over three orders of magnitude (Bjornn et al. 1968; Foerster 1968), small improvements in juvenile survivorship could yield large increases in population abundance. Hence, an attractive avenue of investigation is to identify and quantify processes which limit growth and survivorship in the freshwater environment and then evaluate the feasibility of improving these conditions (Luecke et al. 1996).

The effects of biotic and abiotic factors on recruitment of Snake River sockeye salmon during the lake-rearing phase have only recently been examined (Luecke and Wurtsbaugh 1993; Budy et al. 1994, 1995). These efforts have focused on the effects of competition and decreased productivity in the nursery lakes, and simulation models have been constructed to evaluate the potential for nutrient additions or reductions in resident kokanee biomass to enhance juvenile sockeye salmon production (Luecke et al. 1996).

Estimates of population abundance and temporal changes in distribution of juvenile sockeye salmon are critical elements in any evaluation of the carrying capacity of lakes or the effect of predation on smolt production (Beauchamp et al. 1995; Luecke et al. 1996). In this study, we estimated the abundance of different size-classes of sockeye salmon and kokanee in five Sawtooth Valley lakes and described diel changes in their distribution. We then examined diel distributional 
TABLE 1.-Limnological features and fish assemblages (LT = lake trout, BLT = bull trout, BKT = brook trout, $\mathrm{RBT}=$ rainbow trout, $\mathrm{CT}=$ cutthroat trout, $\mathrm{SK}=$ sockeye salmon or kokanee, MW = mountain whitefish, NS $=$ northern squawfish, $\mathrm{RS}=$ redside shiners, $\mathrm{MS}=$ mountain suckers) of the five study lakes in the Sawtooth Valley.

\begin{tabular}{|c|c|c|c|c|c|}
\hline Lake & Species & $\begin{array}{c}\text { Area } \\
\left(\mathrm{km}^{2}\right)\end{array}$ & $\begin{array}{c}\text { Maxi- } \\
\text { mum } \\
\text { depth } \\
(\mathrm{m})\end{array}$ & $\begin{array}{c}\text { Mean } \\
\text { depth } \\
\text { (m) }\end{array}$ & $\begin{array}{c}\text { Mean } \\
\text { Secchi } \\
\text { depth } \\
\text { (m) }\end{array}$ \\
\hline Redfish & $\begin{array}{l}\text { BLT, NS, } \\
\text { RBT, MW, } \\
\text { SK, RS }\end{array}$ & 6.15 & 92 & 41 & 13.6 \\
\hline Alturas & $\begin{array}{c}\text { LT, BLT, } \\
\text { NS, RBT, } \\
\text { BKT, MW, } \\
\text { SK, RS }\end{array}$ & 3.38 & 53 & 33 & 13.0 \\
\hline Pettit & $\begin{array}{c}\text { RBT, BKT, } \\
\text { SK, RS }\end{array}$ & 1.62 & 52 & 28 & 15.0 \\
\hline Stanley & $\begin{array}{l}\text { LT, BKT, } \\
\text { RBT, SK, } \\
\text { RS }\end{array}$ & 0.81 & 26 & 16 & 7.9 \\
\hline Yellow Belly & BKT, CT & 0.73 & 26 & 13 & 12.3 \\
\hline
\end{tabular}

patterns under different regimes of light, temperature, zooplankton density, and predator density and related these to summer growth and growth efficiency.

Because this assessment involved an endangered stock, only minimal sampling with nets was allowed. Thus, we emphasized electronic sampling of the populations and supplemented our findings with additional biological sampling. Hydroacoustic assessment techniques are well suited for this task and provide the capability of sampling over larger spatial and temporal scales with finer-grain resolution than is possible with conventional sampling techniques that use nets (Thorne 1983). However, hydroacoustic data do not identify the species composition of targets when the limnetic assemblage contains multiple species of overlapping size and spatial distributions. Therefore, our challenge was to discriminate among limnetic species with minimal direct capture data.

\section{Study Area}

The Sawtooth Valley lakes are located in the headwaters of the Salmon River in the Sawtooth National Recreational Area in central Idaho. The five study lakes, Redfish, Alturas, Pettit, Stanley, and Yellow Belly, are small to medium sized, dimictic, and oligotrophic (Table 1) and have summer epilimnetic temperatures of $14-18^{\circ} \mathrm{C}$. Budy et al. (1995) provided a detailed limnological description of these lakes. The lakes contain variable fish assemblages comprised of lake trout Salvelinus namaycush, bull trout $S$. confluentus, brook trout S. fontinalis, rainbow trout Oncorhynchus mykiss, kokanee and sockeye salmon, mountain whitefish Prosopium williamsoni, northern squawfish Ptychocheilus oregonensis, redside shiners Richardsonius balteatus, and mountain suckers Catostomus platyrhynchus. Fish were removed from Yellow Belly Lake with toxicants in 1990, and the lake was restocked with cutthroat trout $O$. clarki with the intention of maintaining the population as broodstock. Barriers were installed on outlet streams of Pettit, Stanley, and Yellow Belly lakes to block passage of nongame fishes from the outlet streams into these lakes.

\section{Methods}

We measured nocturnal abundance and examined the diel vertical distribution patterns of different-sized acoustic targets using dual-beam hydroacoustic techniques (Burczynski and Johnson 1986). Data were collected with a BioSonics model 105 scientific echo sounder with a $420-\mathrm{kHz}$ dual-beam $\left(6^{\circ}, 15^{\circ}\right)$ transducer towed in a fin 0.75 $\mathrm{m}$ deep off the port bow of a 7-m boat. Data were simultaneously recorded directly into computer files with ESP 2.0 dual-beam signal-processing software and onto digital audio tapes (DAT) through a BioSonics model 171 recording interface. Data were sampled at a rate of 2 pings/s traveling $4 \mathrm{~m} / \mathrm{s}$. We used a $0.4-\mathrm{ms}$ pulse width and a receiver sensitivity gain of 12 decibels (dB). Alturas and Redfish lakes were surveyed on September 13-15, 1991. Eight transects were sampled in each lake in 1991, both during daylight (40-50\% cloud cover) and at night after moonset. In 1992, we sampled 5-14 transects across each lake during moonless nights on September 24-26 (Figure 1) and 2-9 transects during day and dusk periods on Redfish, Alturas, and Yellow Belly lakes. Daylight transects were surveyed until an hour before sunset. Dusk transects were surveyed from sunset until astronomical twilight, and night transects were only surveyed during moonless periods starting no earlier than $30 \mathrm{~min}$ after astronomical twilight at dusk and ending no later than $30 \mathrm{~min}$ before astronomical twilight at dawn. Levy (1990) and Luecke and Wurtsbaugh (1993) demonstrated that vertical distribution patterns remained relatively constant during day and night but were dynamic during crepuscular periods. Temperature and dissolved oxygen profiles were measured during the surveys on each lake.

Acoustic data were processed by dual-beam 

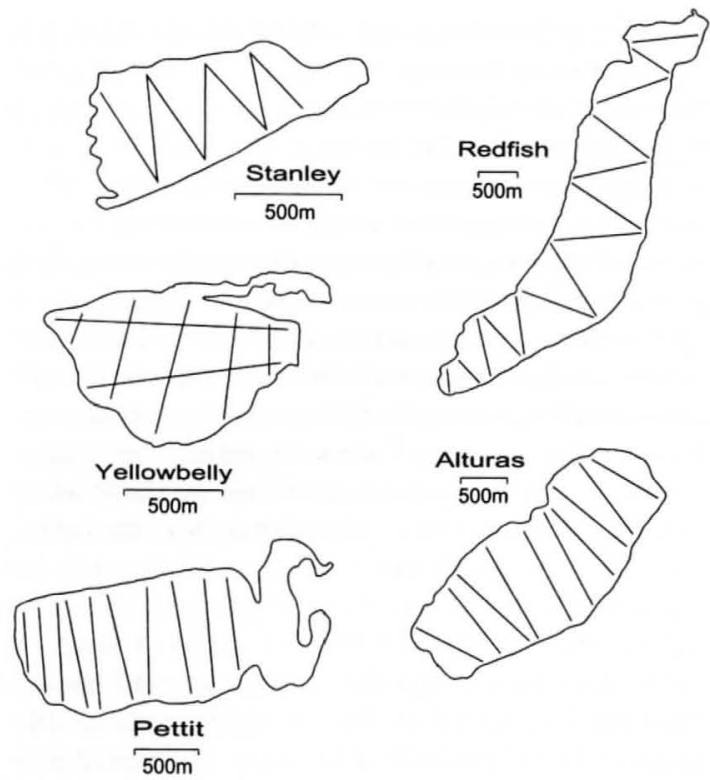

FIGURE 1.-Map of the study lakes in the Sawtooth Valley indicating the hydroacoustic transects. All lakes were surveyed at night except Yellow Belly Lake where daytime transects were more appropriate for cutthroat and brook trout. Note the different scales for each lake.

echo counting and echo integration in 1991 and echo counting alone in 1992. When echo counting, we used a time-varied gain (TVG) signal amplification of $40 \log _{10} R$ (range to target). We analyzed dual-beam target densities by depth for three sizeclasses: -59 to $-51 \mathrm{~dB}$ (age-0 sockeye salmon and kokanee, approximately $3-8 \mathrm{~cm}$ total length), -51 to $-43 \mathrm{~dB}$ (age-1 sockeye salmon and kokanee, $8-17 \mathrm{~cm}$ ), and -43 to $-30 \mathrm{~dB}$ (older kokanees and potentially piscivorous fishes $>17 \mathrm{~cm}$ total length; Love 1977; Dahm et al. 1985). Target strength frequency distributions were calculated from the mean target strengths of targets that could be tracked over successive pings. Dual-beam target strength estimates were calibrated before each survey by pinging on a ping pong ball at $4-10 \mathrm{~m}$ below the transducer. Analyses were only performed on echoes within $3^{\circ}$ of the acoustic axis ( $-6 \mathrm{~dB}$ off axis) that met predetermined singleecho criteria $(6 \mathrm{~dB}$ above depth-specific noise level and $6 \mathrm{~dB}$ below the bottom signal threshold of 7 $\mathrm{V} ; 0.40-0.52 \mathrm{~ms}$ echo pulse width at half-signal amplitude). These criteria excluded detection of multiple targets while echo counting, so echo integration was used to identify schooling targets (Luecke and Wurtsbaugh 1993). Analyses were stratified by $5-\mathrm{m}$ depth intervals from 0 to $30 \mathrm{~m}$
TABLE 2.-Midwater trawl catches of Oncorhynchus nerka and redside shiner (number of fish/5-min trawl) by depth interval during August and September 1992. Parenthetical values are 2 SEs; $N$ is the number trawls.

\begin{tabular}{rrcl}
\hline $\begin{array}{c}\text { Trawl } \\
\text { depth } \\
(\mathrm{m})\end{array}$ & $N$ & O. nerka & Redside shiner \\
\hline \multicolumn{3}{c}{ Redfish Lake } \\
$4-29$ & 4 & $0.61(0.28)$ & $0.00(0.00)$ \\
$12-29$ & 4 & $1.35(0.39)$ & $0.00(0.00)$ \\
$12-16$ & 2 & $0.78(0.78)$ & $0.19(0.38)$ \\
$22-24$ & 2 & $2.00(3.33)$ & $0.00(0.00)$ \\
& & Alturas Lake & \\
$3-24$ & 1 & 5.68 & 0.00 \\
$12-30$ & 6 & $5.60(1.76)$ & 0.00 \\
$17-18$ & 1 & 0.17 & 0.00 \\
$24-24$ & 1 & 7.50 & 0.00 \\
$28-28$ & 1 & 13.33 & 0.00 \\
$30-30$ & 1 & 11.67 & 0.00 \\
& & Pettit Lake & \\
$10-12$ & 1 & 0.00 & 1.25 \\
$12-20$ & 2 & $0.56(1.11)$ & $0.00(0.00)$ \\
$18-20$ & 1 & 0.70 & 0.00 \\
& & Stanley Lake & \\
16 & 1 & 2.00 & 1.00 \\
12 & 4 & $1.96(1.77)$ & $0.97(1.36)$ \\
\hline
\end{tabular}

and by $10-\mathrm{m}$ intervals from 30 to $60 \mathrm{~m}$ (up to 90 $\mathrm{m}$ in the deepest lakes). Echoes less than 0.5 and $1.0 \mathrm{~m}$ from the bottom were excluded from echo counting and echo integration, respectively. For echo integration in 1991, we used a $20 \log _{10} R$ TVG and the mean backscattering cross-section $\left(0.000022 \mathrm{~V}^{2}\right.$; corresponding to a $7-\mathrm{cm}$ fish weighing $3.1 \mathrm{~g}$ ) of individual targets from the dual-beam analysis to convert integrated voltages within each depth interval into fish density.

Midwater trawl samples were taken on the same nights as the hydroacoustic surveys to verify the species and size composition of the acoustic targets during the 1992 survey. Idaho Department of Fish and Game biologists trawled along the longitudinal axis of each lake (except Yellow Belly Lake, which was inaccessible to the trawling boat). The midwater otter trawl had a cross-sectional mouth area of $9.3 \mathrm{~m}^{2}$ (with a vertical opening of approximately $3 \mathrm{~m}$ ) and $3-\mathrm{mm}$ knotless mesh in the cod end. The trawl was towed at $1.0 \mathrm{~m} / \mathrm{s}$ in steps (generally $5 \mathrm{~min} / \mathrm{step}$ ) through a range of depths containing targets (e.g., Parkinson et al. 1994; B. E. Rieman, U.S. Forest Service, unpublished). When acoustic targets occupied a broad range of depths, a series of stepped trawls sampled different depth intervals (Table 2). When other species were mixed with limnetic sockeye salmon 
or kokanee, they were proportionally allocated across the hydroacoustic estimates of fish density for targets of similar size.

We examined the agreement between fish densities in midwater trawls and hydroacoustic target densities by regression. Fish densities from trawls that sampled a narrow depth band (0-2 $\mathrm{m}$ difference in towing depth for the upper beam of the trawl translates into a $3-5 \mathrm{~m}$ vertical sampling interval) were paired with acoustic target densities measured from the corresponding depth interval. Trawl catches were standardized for a 5-min haul; acoustic target densities were reported as number of targets $/ 1,000 \mathrm{~m}^{3}$. Regressions were performed on both the standardized densities and on transformations of these by $\log _{10}$ (trawl catch +1 ) and $\log _{10}$ (acoustic density +1$)$. When replicate trawls had been taken, the mean was paired with the acoustic density estimate because individual replicates could not be assigned to different acoustic density measurements. Ten pairs of trawl and acoustic densities were used in this analysis. To examine the effect of fish or target size, total fish density in trawls was regressed against densities for different size ranges of acoustic targets (all targets $>3 \mathrm{~cm}, 3-7 \mathrm{~cm}$ targets, 3-18 cm targets, $7-18 \mathrm{~cm}$ targets, and targets $>18 \mathrm{~cm}$ ). Pearson's correlation coefficient was computed and considered significant at $P \leq 0.05$.

Potential predators and competitors were sampled with sinking horizontal gill nets in Alturas, Pettit, and Stanley lakes in mid-September 1992. Redfish Lake was sampled with gill nets in July 1991, and Yellow Belly Lake was sampled in June 1992. The nets were $37 \times 2 \mathrm{~m}$ with panels of $38-$, 51-, 64-, 76-, 89-, and 102-mm stretched mesh. Six to eight nets were set for $24 \mathrm{~h}$ in two quadrants of each lake one night and reset in the two remaining quadrants the following night. In each quadrant, nets were set perpendicular to shore in three depth intervals: $2-10 \mathrm{~m}, 11-20 \mathrm{~m}$, and $>20$ $\mathrm{m}$. An additional net was occasionally set parallel to shore in one of these depth intervals. The catch per net hour was recorded for each species. Lengths and weights were measured and stomach contents removed for future analysis. We used gillnet catch per unit effort (CPUE) as an index of potential competition and predation risk for juvenile sockeye salmon and kokanee in each lake because the relative density of potential piscivores could alter diel distribution patterns of juvenile fish. Although CPUE from sinking gill nets deployed in sloping regions nearshore did not necessarily reflect densities or distributions of fishes in limnetic regions, these data described the depth distribution of various species, which was helpful for interpreting distribution patterns of the larger pelagic targets in the hydroacoustic data.

Vertical distribution patterns could be influenced by food supply and predation risk across vertical thermal and light gradients. To determine how potential smolt production could be affected by different combinations of these factors, we plotted nocturnal thermal exposure, body size, and growth efficiency against the ratio of food supply to predation risk. Food supply data were available for each lake as crustacean zooplankton density $(\mu \mathrm{g} / \mathrm{L})$ from Luecke et al. (1996). We used piscivore CPUE (catch per overnight gill-net set) in the upper $20 \mathrm{~m}$ as an index of piscivore density and predation risk for juvenile $O$. nerka. Nocturnal thermal exposure was the mean temperature experienced by age- 0 O. nerka during a moonless night and was calculated as the sum of the products of the proportions of the population in each depth interval multiplied by the mean temperature within each depth interval. Growth efficiencies were computed as proportions of the maximum growth that could be attained by each population, given the food supply and thermal structure of each lake. A growth model by Budy and Luecke (1994) estimated daily consumption of age- 0 O. nerka in each lake as the proportion $(\mathrm{P})$ of the temperature-specific maximum consumption:

$$
\mathrm{P}=(0.035 \cdot \mathrm{ZB}) /(1+0.077 \cdot \mathrm{ZB}),
$$

where ZB is crustacean zooplankton biomass $(\mu \mathrm{g} /$ L). We used the bioenergetics model of Hewett and Johnson (1992) for sockeye salmon (Beauchamp et al. 1989) to estimate growth at the temperatures associated with the observed diel vertical distribution pattern in each lake. Model simulations were repeated to find the temperatures that maximized growth at the ration size estimated for each lake. The ratio of growth under the thermal experience estimated from observed vertical distribution versus the thermal experience that would maximize growth at that ration provided our estimate of growth efficiency. In this context, growth efficiency measured how well $O$. nerka select temperatures that maximized growth under limited rations and other ecological constraints.

\section{Results}

\section{Species Composition and Size Structure}

Nocturnal midwater trawls in Redfish, Alturas, Pettit, and Stanley lakes caught 494 juvenile $O$. nerka (44-240 mm total length) but only 18 red- 


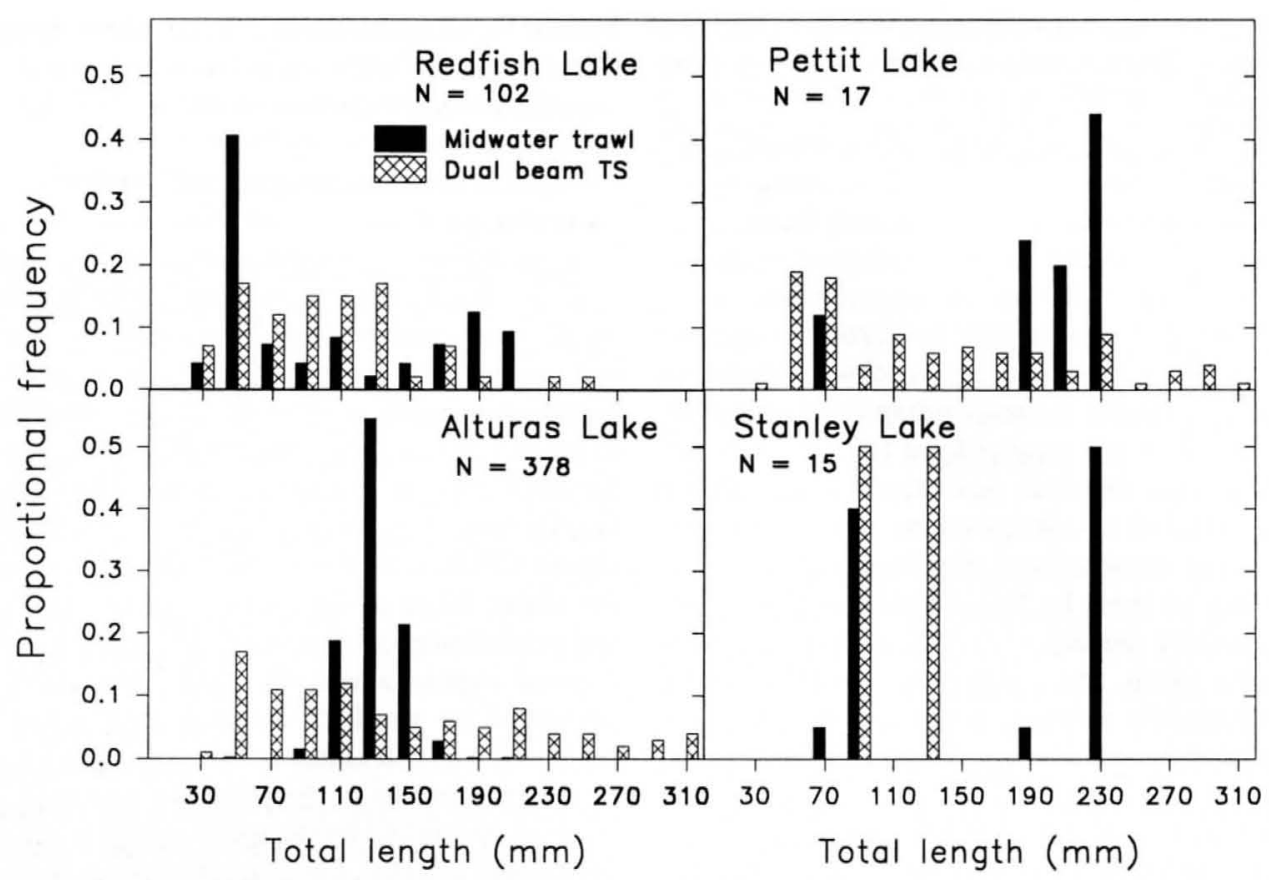

FIGURE 2.-Length frequency histograms of sockeye salmon and kokanee from midwater trawl catches and dualbeam estimates of target strength (TS) that were converted to fish length by using the regression equations of Love (1977) and Dahm et al. (1985); $N=$ number of fish sampled by midwater trawls in each lake. In Pettit Lake, the midwater trawl did not sample the shallow layer of small redside shiners which contributed most to the small size mode.

side shiners $(80-90 \mathrm{~mm})$, which suggested that the nocturnal limnetic communities in these lakes were dominated by $O$. nerka (Table 2 ). The size distribution of acoustic targets consistently showed that the frequency of small targets was greater than or similar to the frequency of larger targets; however, correspondence between size modes in acoustic and midwater trawl data varied among lakes (Figure 2). In Redfish Lake, three size-classes with modal lengths of 60,120 , and $200 \mathrm{~mm}$ were encountered in midwater trawl samples. Although not as distinct as the size modes from midwater trawl samples, the frequency distribution of mean target strengths (converted to total lengths) from tracked acoustic targets closely corresponded to the size distribution of the two smaller size modes in midwater trawl samples from Redfish Lake (Figure 2). The acoustic data underestimated total lengths for the largest fish in the trawl by $15 \mathrm{~mm}$ (Figure 2). In Pettit Lake, acoustic size distributions reflected the smallest (70-90 $\mathrm{mm})$ and largest $(210-230 \mathrm{~mm})$ size modes observed in the midwater trawl and overlapped with, but underestimated, the 170-190-mm size mode in the trawl by $20-40 \mathrm{~mm}$. In Alturas Lake, the acoustic size distribution revealed a relatively strong mode of small $(50-70 \mathrm{~mm})$ targets, whereas the trawl only captured one $50-\mathrm{mm}$ kokanee. The strong $90-170-\mathrm{mm}$ size mode in the trawl sample was underestimated by $20 \mathrm{~mm}$ in the acoustic sizefrequency distribution. In Stanley Lake, comparisons were compromised by low sample sizes in both the trawl and trackable targets. Only four targets could be tracked over successive pings, but the smaller size mode in the trawl sample (70-90 $\mathrm{mm}$ ) corresponded with half of these. Larger fish from the trawl did not correspond with either of the remaining tracked targets, but they did correspond directly with the larger size mode of single-ping acoustic targets.

Midwater trawl catches were not significantly correlated $(P=0.09-0.58)$ with the corresponding acoustic target densities in the same depth intervals (Table 3); however, the low number of paired measurements $(N=10)$ reduced the strength of these comparisons. Regressions that used transformed data did not improve the relationships. Correlations were highest when comparing only the densities of the smallest acoustic targets (3-7 $\mathrm{cm}$ ) with trawl catches. This relationship worsened 
TABLE 3.-Comparison of trawl catch per 5-min haul and acoustic target density (targets $/ 1,000 \mathrm{~m}^{3}$ ) when the trawl sampled narrow, discrete depth intervals. The regression equation was acoustic density $=a+b \cdot($ catch $/ 5$ min trawl). Significance level was $P=0.05$ for $8 \mathrm{df}$ at $R$ $=0.632\left(R^{2}=0.40\right)$.

\begin{tabular}{ccccc}
\hline $\begin{array}{c}\text { Target } \\
\text { size } \\
(\mathrm{cm})\end{array}$ & $\begin{array}{c}\text { Intercept } \\
(a)\end{array}$ & $\begin{array}{c}\text { Slope } \\
(b)\end{array}$ & $r^{2}$ & $P$ \\
\hline$>3$ & 2.5019 & 0.2408 & 0.17 & 0.29 \\
$3-7$ & 0.5613 & 0.1143 & 0.38 & 0.09 \\
$3-18$ & 1.3260 & 0.2030 & 0.30 & 0.15 \\
$7-18$ & 0.7647 & 0.0887 & 0.22 & 0.22 \\
$>18$ & 1.1758 & 0.0377 & 0.02 & 0.58 \\
\hline
\end{tabular}

when either larger targets or a broader size-range of targets were included in the regression, which suggested increased trawl avoidance by larger fish.

The catch rates and species composition of potential predators and competitors in gill nets along shore slope zones varied among lakes (Table 4). In Alturas Lake, northern squawfish and mountain sucker were the predominant species nearshore in depths of $0-20 \mathrm{~m}$, followed by rainbow trout. The catch rate of northern squawfish in Alturas Lake was at least three times higher than for all potential piscivores in any of the other lakes (Table 4). Compared with northern squawfish in Alturas, we encountered lower catch rates of rainbow trout and brook trout in Pettit Lake, and of brook trout and lake trout in Stanley Lake. In all lakes, catches of large piscivores were greatest in shallower depth strata. These species might also occupy these shallower depths $(0-20 \mathrm{~m})$ offshore, but were invulnerable to the midwater trawl.

\section{Diel Patterns in Horizontal and Vertical Distribution}

Dual-beam echo-counting data indicated that the diel horizontal and vertical distribution of targets varied among lakes and by fish size. The species composition of targets were inferred from those observed in midwater trawl samples (Table 2; Figure 2), the size-specific depth distribution of acoustic targets, and the association of targets with offshore or shore slope regions of the acoustic transects.

Redfish Lake.-Acoustic targets showed a pronounced diel vertical migration pattern in Redfish Lake (Figures 3, 4). Few single targets were detected during midday with the dual-beam technique (Figure 3), and echograms indicated that most single targets were closely associated with the slope zone around the perimeter of the lake. Echo integration data in 1991 indicated that most pelagic targets were concentrated in schools at 25$30 \mathrm{~m}$ during daylight (Figure 4) and thus could not be detected by the dual beam processor because only single-fish targets were accepted for analysis. At dusk and during the night, schools dispersed and fish entered the mid and upper water column (Figures 3, 4). The smallest fish $(3-7 \mathrm{~cm}$ ) concentrated in warmer epilimnetic waters at dusk

TABLE 4.-Mean (SE) depth-specific catch per overnight gill-net set for each of the Sawtooth Valley lakes; $N=$ the number of nets. Only catch summaries were available for Redfish Lake, so SE could not be computed.

\begin{tabular}{|c|c|c|c|c|c|c|c|c|c|c|c|}
\hline $\begin{array}{l}\text { Depth } \\
\text { (m) }\end{array}$ & $N$ & $\begin{array}{l}\text { Bull } \\
\text { trout }\end{array}$ & $\begin{array}{l}\text { Lake } \\
\text { trout }\end{array}$ & $\begin{array}{c}\text { Mountain } \\
\text { sucker }\end{array}$ & $\begin{array}{l}\text { Mountain } \\
\text { white- } \\
\text { fish }\end{array}$ & $\begin{array}{l}\text { Northern } \\
\text { squawfish }\end{array}$ & $\begin{array}{c}\text { Rainbow } \\
\text { trout }\end{array}$ & $\begin{array}{c}\text { Brook } \\
\text { trout }\end{array}$ & $\begin{array}{l}\text { Cut- } \\
\text { throat } \\
\text { trout }\end{array}$ & O. nerka & $\begin{array}{c}\text { Redside } \\
\text { shiner }\end{array}$ \\
\hline \multicolumn{12}{|c|}{ Redfish Lake, Jul 1991} \\
\hline $0-20$ & 14 & 3.2 & 0.0 & 44.9 & 0.1 & 3.9 & 7.4 & 0.0 & 0.0 & 0.0 & 0.0 \\
\hline \multicolumn{12}{|c|}{ Alturas Lake, Sep 1992} \\
\hline $0-10$ & 4 & $1.5(0.6)$ & 0.0 & $23.3(11.5)$ & $1.0(0.4)$ & $23.3(7.0)$ & $4.0(2.3)$ & $0.0(0.0)$ & 0.0 & $0.0(0.0)$ & $0.5(0.5)$ \\
\hline $10-20$ & 5 & $1.8(0.8)$ & 0.0 & $26.6(9.1)$ & $0.6(0.6)$ & $21.8(2.1)$ & $3.6(0.7)$ & $0.2(0.2)$ & 0.0 & $0.2(0.2)$ & $0.0(0.0)$ \\
\hline $20-30$ & 3 & $1.3(0.7)$ & 0.0 & $6.3(2.2)$ & $2.3(1.5)$ & $2.7(1.8)$ & $0.0(0.0)$ & $0.0(0.0)$ & 0.0 & $1.0(1.0)$ & $0.0(0.0)$ \\
\hline $30-40$ & 4 & $1.5(0.6)$ & 0.0 & $0.8(0.5)$ & $0.3(0.3)$ & $0.0(0.0)$ & $0.0(0.0)$ & $0.0(0.0)$ & 0.0 & $0.3(0.3)$ & $0.0(0.0)$ \\
\hline \multicolumn{12}{|c|}{ Pettit Lake, Sep 1992} \\
\hline $0-10$ & 6 & 0.0 & 0.0 & 0.0 & 0.0 & 0.0 & $2.7(1.0)$ & $2.8(1.4)$ & 0.0 & $0.0(0.0)$ & $2.0(1.4)$ \\
\hline $10-20$ & 6 & 0.0 & 0.0 & 0.0 & 0.0 & 0.0 & $0.2(0.2)$ & $1.5(0.8)$ & 0.0 & $0.8(0.4)$ & $1.0(1.0)$ \\
\hline $20-30$ & 4 & 0.0 & 0.0 & 0.0 & 0.0 & 0.0 & $0.0(0.0)$ & $0.0(0.0)$ & 0.0 & $0.0(0.0)$ & $0.0(0.0)$ \\
\hline \multicolumn{12}{|c|}{ Stanley Lake, Sep 1992} \\
\hline $0-10$ & 3 & 0.0 & $3.0(0.0)$ & 0.0 & 0.0 & 0.0 & $8.7(4.5)$ & $4.7(1.5)$ & 0.0 & $0.3(0.3)$ & 0.0 \\
\hline $10-20$ & 6 & 0.0 & $2.7(1.1)$ & 0.0 & 0.0 & 0.0 & $0.5(0.5)$ & $0.0(0.0)$ & 0.0 & $0.2(0.2)$ & 0.0 \\
\hline $20-30$ & 3 & 0.0 & $0.0(0.0)$ & 0.0 & 0.0 & 0.0 & $0.0(0.0)$ & $0.0(0.0)$ & 0.0 & $0.0(0.0)$ & 0.0 \\
\hline \multicolumn{12}{|c|}{ Yellow Belly Lake, Jun 1992} \\
\hline $0-20$ & 2 & 0.0 & 0.0 & $1.0(0.5)$ & 0.0 & 0.0 & 0.0 & $6.0(0.0)$ & $9.0(2.0)$ & 0.0 & 0.0 \\
\hline
\end{tabular}




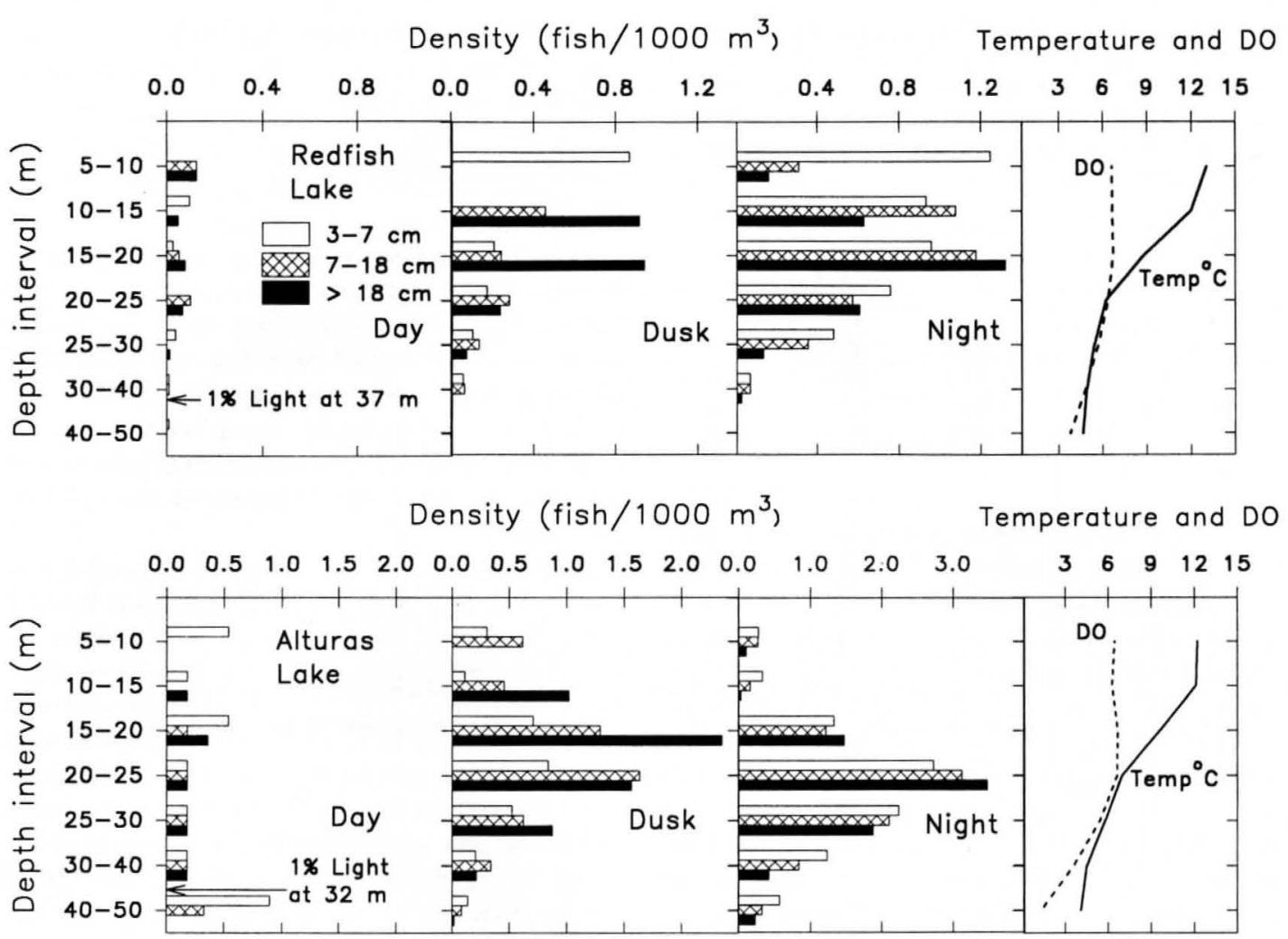

FIGURE 3.-Diel distribution of three size-classes of fish in Redfish Lake (top) and Alturas Lake (bottom) during September 1992. Data were collected and analyzed by means of dual-beam echo-counting techniques. Vertical profiles of temperature $\left({ }^{\circ} \mathrm{C}\right)$ and dissolved oxygen $(\mathrm{DO}, \mathrm{mg} / \mathrm{L})$ for each lake are displayed in the far right panels.

(shallower than $10 \mathrm{~m}$ ); they were more broadly distributed throughout the water column at night but were still more numerous toward the surface (Figure 3). Larger targets $(\geq 7 \mathrm{~cm}$ ) remained in the metalimnion (10-25 m; Figure 3). This distribution pattern resulted in average daily temperatures of $9.7^{\circ} \mathrm{C}, 9.4^{\circ} \mathrm{C}$, and $9.5^{\circ} \mathrm{C}$ experienced by small, medium, and large $O$. nerka, respectively.

Alturas Lake.-Daytime pelagic target densities were much lower than during the dusk and night periods in Alturas Lake (Figures 3,4). During daylight, all targets shallower than $10 \mathrm{~m}$ were located in the slope zone and, according to gill-net catches, were probably northern squawfish, various trout species, mountain whitefish, or mountain suckers (Table 4). Unlike Redfish Lake, pelagic fish schools were not detected by echo integration during daylight (Figure 4). Thus, the difference between low pelagic fish densities during daylight and the relatively high densities at night were best explained by dispersal from the bottom and perimeter slopes into the limnetic zone at dusk and during the night. Targets were mostly distributed over
5-30 $\mathrm{m}$ at dusk, and peak concentrations occurred at $15-25 \mathrm{~m}$ for all size-classes. Most targets shifted slightly deeper at night to depths of $15-40 \mathrm{~m}$. Limnetic densities were 2-5 times greater in Alturas Lake than in Redfish Lake, but small targets remained much deeper in Alturas Lake throughout the diel cycle in both 1991 and 1992 (Figures 3, 4). Although temperatures up to $12.2^{\circ} \mathrm{C}$ were available above $15 \mathrm{~m}$, the mean daily temperatures experienced by small, medium, and large $O$. nerka were $7.3^{\circ} \mathrm{C}, 6.6^{\circ} \mathrm{C}$, and $7.6^{\circ} \mathrm{C}$ as a consequence of the diel vertical distribution pattern observed in September 1992.

Pettit Lake.-The vertical distribution of targets in Pettit Lake at night was bimodal; predominantly, smaller targets were in the shallower mode $(\leq 10 \mathrm{~m})$ and larger targets were in the deeper mode (10-15 m; Figure 5). Based on midwater trawl (Table 2) and gill-net catches (Table 4), the shallower small- and medium-sized targets were predominantly redside shiners, whereas deeper targets were $O$. nerka. Redside shiners were clearly identified by spotlighting along the shore slopes 


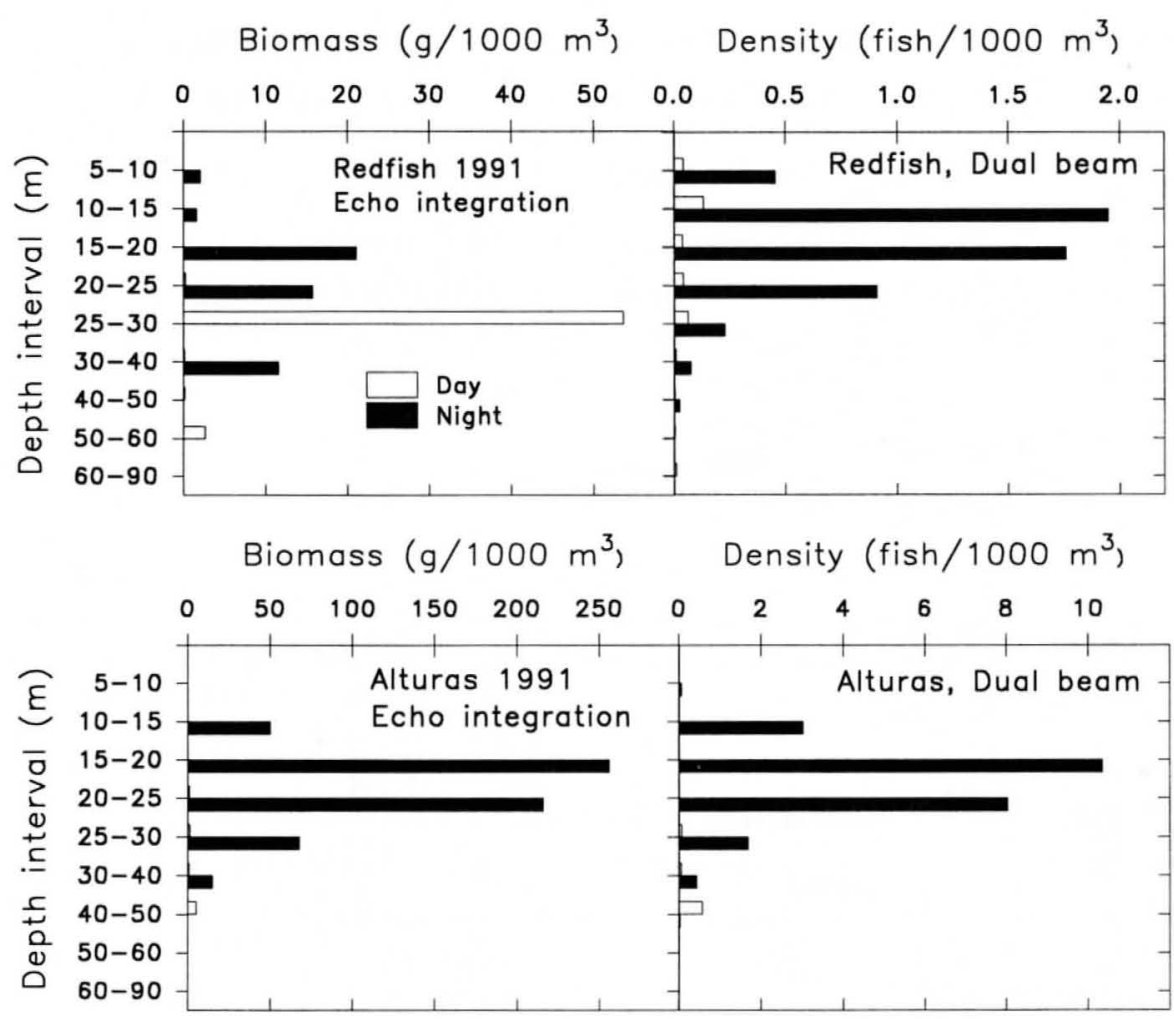

FIGURE 4.-Comparison of day-night distribution patterns detected by means of echo integration (left) and dualbeam echo-counting (right) techniques in Redfish Lake (top) and Alturas Lake (bottom) during September 1991. The dual-beam system excludes multiple targets and thus cannot detect fish schools (see Redfish Lake during daylight at 25-30 m), whereas echo integration cannot determine target size.

where these small, shallow targets were detected by the echo sounder at night. Although fish densities varied among nocturnal transects within lakes, the differences were only prominent in Pettit Lake. Densities along transects $8-10$ averaged 10 -fold higher than elsewhere in the lake and were caused by aggregations of redside shiners along the shore slope (ANOVA and Student-NewmanKeuls multiple range test, $P<0.05)$. The nocturnal depth modes for all sizes of $O$. nerka in Pettit Lake were located near the top of the thermocline, resulting in a mean nocturnal temperature of 11.8 $11.9^{\circ} \mathrm{C}$

Stanley Lake.-Nocturnal densities of all acoustic targets were concentrated in the upper water column (Figure 5). Few targets were found below $15 \mathrm{~m}$; dissolved oxygen concentrations declined rapidly from $6.7 \mathrm{mg} / \mathrm{L}$ at $15 \mathrm{~m}$ to $0.9 \mathrm{mg} / \mathrm{L}$ at 25 $\mathrm{m}$. The nocturnal depth modes for all sizes of $O$. nerka were located near the top of the thermocline, resulting in mean nighttime temperatures of $11.0-11.1^{\circ} \mathrm{C}$.
Yellow Belly Lake.-In contrast to the lakes containing sockeye salmon and kokanee, the limnetic fish density in Yellow Belly Lake was highest during the day, and targets were concentrated in the upper epilimnion $(\leq 5 \mathrm{~m})$; target density declined at dusk, but included more small $(3-7 \mathrm{~cm})$ targets (Figure 6). Limnetic targets were virtually nonexistent at night. This coincided with our observations of widespread surface-feeding activity during daylight and dusk and the almost complete absence of surface feeding at night. This epilimnetic distribution afforded all size-classes full access to optimal $12-13^{\circ} \mathrm{C}$ temperatures (Dwyer and Kramer 1975) during daylight and dusk. The absence of limnetic targets at night, coupled with the lack of surface activity, suggests that cutthroat trout and brook trout settled onto the bottom by moving either deeper or onshore. Dissolved oxygen concentrations were high enough $(>5.0 \mathrm{mg} / \mathrm{L})$ that all depths throughout the lake were habitable, but temperatures dropped rapidly below optimum in waters deeper than $15 \mathrm{~m}$. 

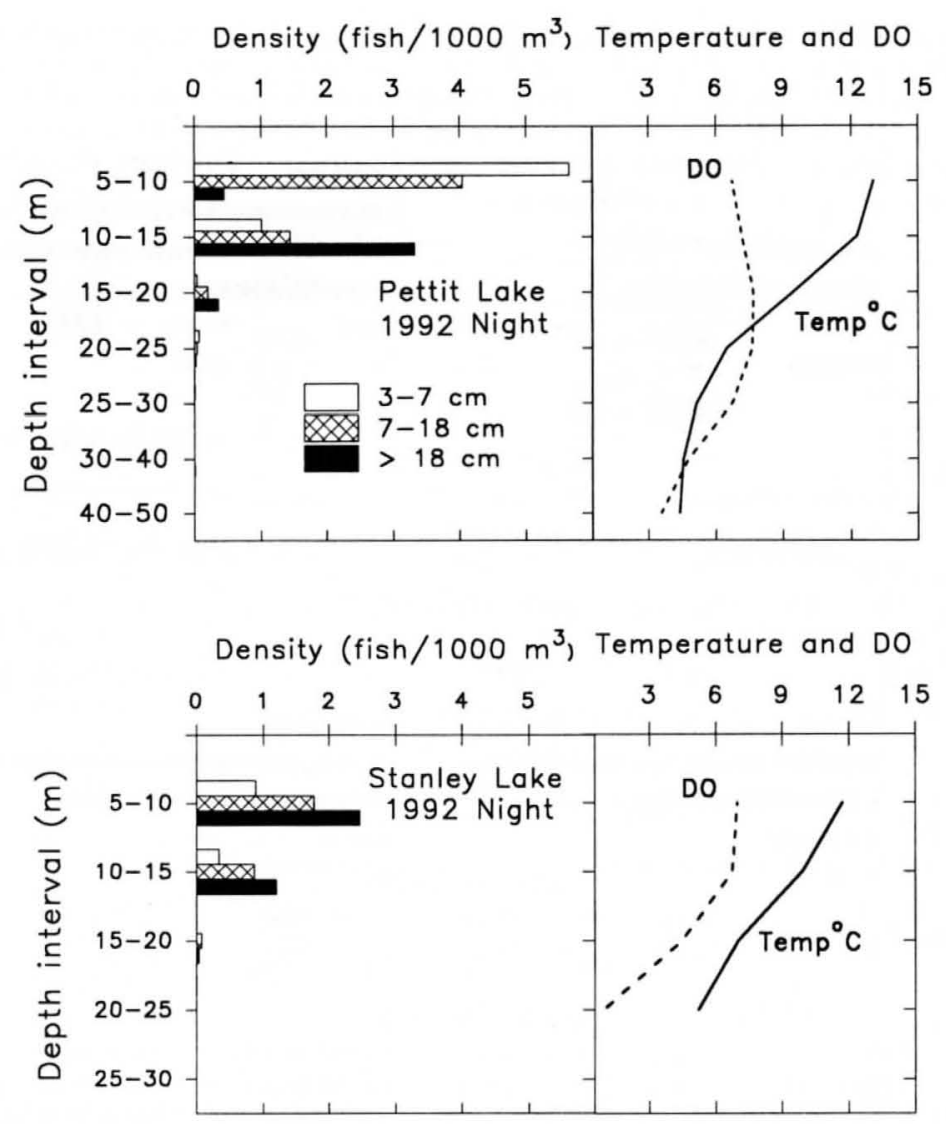

FIGURE 5.-Nocturnal distribution of three size-classes of fish in Pettit Lake (top) and Stanley Lake (bottom) during September 1992. Data were collected and analyzed by means of dual-beam echo-counting techniques. Vertical profiles of temperature $\left({ }^{\circ} \mathrm{C}\right)$ and dissolved oxygen $(\mathrm{DO}, \mathrm{mg} / \mathrm{L})$ for each lake are displayed in the right-hand panels.

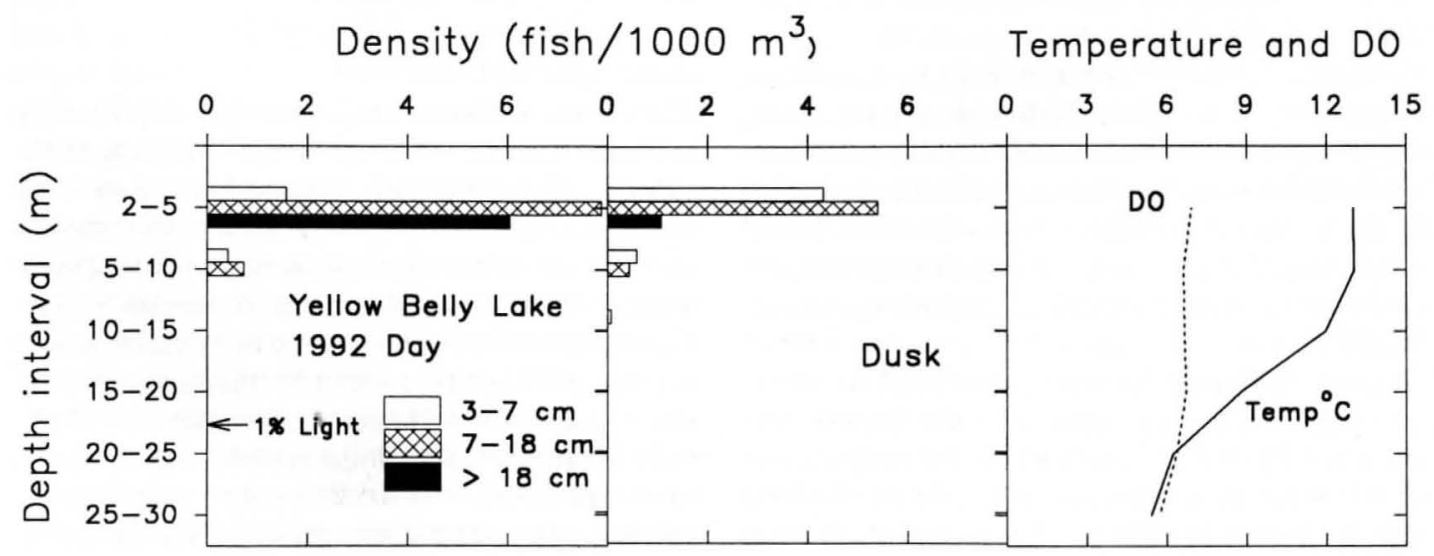

FIGURE 6.-Vertical distribution of three size-classes of fish in Yellow Belly Lake during daylight and dusk in September 1992. Data were collected and analyzed by means of dual-beam echo-counting techniques. Vertical profiles of temperature $\left({ }^{\circ} \mathrm{C}\right)$ and dissolved oxygen $(\mathrm{DO}, \mathrm{mg} / \mathrm{L})$ are displayed in the far right panel. No $O$. nerka inhabit this lake; the predominant species are cutthroat trout and brook trout. 
TABLE 5.-Hydroacoustic estimates of abundance and density of all limnetic fish by target size in Redfish and Alturas lakes in September 1991 and all five study lakes in September 1992. Total abundance estimates were partitioned into values for $O$. nerka and redside shiners based on depth-specific midwater trawl catches, and depth-target strengthhabitat associations. Targets in Yellow Belly Lake were cutthroat trout and brook trout. Acoustic targets were not partitioned into different species in 1991 because midwater trawl samples were not available.

\begin{tabular}{|c|c|c|c|c|c|c|}
\hline \multirow[b]{2}{*}{ Measure } & \multicolumn{3}{|c|}{ Target abundance by size } & \multirow{2}{*}{$\begin{array}{c}\text { Total } \\
\text { targets }\end{array}$} & \multirow{2}{*}{$\begin{array}{c}\text { Total } \\
\text { o. nerka }\end{array}$} & \multirow{2}{*}{$\begin{array}{l}\text { Total } \\
\text { redside } \\
\text { shiners }\end{array}$} \\
\hline & $3-7 \mathrm{~cm}$ & $7-18 \mathrm{~cm}$ & $>18 \mathrm{~cm}$ & & & \\
\hline \multicolumn{7}{|c|}{ Redfish Lake, 1991} \\
\hline Abundance & 39,209 & 39,913 & 7,278 & 86,400 & & \\
\hline $2 \mathrm{SE}$ & 7,685 & 5,139 & 566 & 13,390 & & \\
\hline Number/ha & 64 & 65 & 12 & 140 & & \\
\hline \multicolumn{7}{|c|}{ Alturas Lake, 1991} \\
\hline Abundance & 78,548 & 139,321 & 12,131 & 230,000 & & \\
\hline $2 \mathrm{SE}$ & 9,867 & 15,328 & 1,820 & 27,015 & & \\
\hline Number/ha & 232 & 412 & 36 & 680 & & \\
\hline \multicolumn{7}{|c|}{ Redfish Lake, 1992} \\
\hline Abundance & 112,665 & 88,355 & 70,983 & 272,003 & 241,500 & 30,504 \\
\hline $2 \mathrm{SE}$ & 53,474 & 34,146 & 26,906 & 114,526 & 105,132 & 9,394 \\
\hline Number/ha & 183 & 144 & 115 & 442 & 393 & 50 \\
\hline \multicolumn{7}{|c|}{ Alturas Lake, 1992} \\
\hline Abundance & 93,024 & 85,327 & 79,111 & 257,462 & 257,462 & 0 \\
\hline $2 \mathrm{SE}$ & 43,779 & 30,486 & 26,738 & 101,003 & 101,003 & 0 \\
\hline Number/ha & 275 & 252 & 234 & 762 & 762 & 0 \\
\hline \multicolumn{7}{|c|}{ Pettit Lake, 1992} \\
\hline Abundance & 41,334 & 34,594 & 23,892 & 99,820 & 36,947 & 62,873 \\
\hline $2 \mathrm{SE}$ & 29,928 & 21,169 & 13,803 & 64,900 & 17,324 & 47,575 \\
\hline Number/ha & 255 & 214 & 147 & 616 & 228 & 388 \\
\hline \multicolumn{7}{|c|}{ Stanley Lake, 1992} \\
\hline Abundance & 3,019 & 6,560 & 8,994 & 18,573 & 12,481 & 6,092 \\
\hline $2 \mathrm{SE}$ & 2,679 & 4,490 & 2,972 & 10,141 & 6,890 & 3,251 \\
\hline Number/ha & 37 & 81 & 111 & 229 & 154 & 75 \\
\hline \multicolumn{7}{|c|}{ Yellow Belly Lake, day transects in 1992} \\
\hline Abundance & 6,373 & 28,541 & 20,539 & 55,453 & 0 & 0 \\
\hline $2 \mathrm{SE}$ & 11,400 & 51,056 & 26,460 & 88,916 & 0 & 0 \\
\hline Number/ha & 87 & 391 & 281 & 760 & 0 & 0 \\
\hline
\end{tabular}

\section{Population Abundance}

For each lake, total limnetic fish abundance was estimated by size-class and partitioned between $O$. nerka and redside shiners (Table 5). For Redfish Lake, the estimated combined abundance (2 SE) of $O$. nerka and redside shiners was 86,400 $(13,390)$ in 1991 . In 1992, estimates were considerably higher: $241,500(105,132)$ for $O$. nerka and $30,504(9,394)$ for redside shiners. In Alturas Lake, we estimated $230,000(27,015) O$. nerka in 1991 and $257,462(101,003) O$. nerka in 1992. We estimated $36,947(17,324) O$. nerka and 62,873 $(47,575)$ redside shiners in Pettit Lake and 12,481 $(6,890)$ O. nerka and 6,092 $(3,251)$ redside shiners in Stanley Lake. In Yellow Belly Lake, the abundance of limnetic cutthroat trout and brook trout was estimated from the daytime survey at 55,453 $(88,916)$.

\section{Vertical Distribution in Relation to Food Supply and Predators}

We evaluated how populations responded to different potential growth and survival conditions by plotting thermal exposure, size at the end of September, and growth efficiency of $O$. nerka against the ratio of zooplankton biomass and piscivore density for each lake. Pettit, Stanley, Redfish, and Alturas lakes represented a gradient of declining zooplankton density and increasing piscivore density (Figure 7) and showed similar thermal stratification patterns in late September (Figures 3, 5). As the ratio of food supply to piscivore density increased, $O$. nerka occupied shallower depths at night and experienced higher temperatures and faster growth; however, growth efficiency declined (Figure 8). Under relatively favorable growth and survival conditions, $O$. nerka emphasized faster 


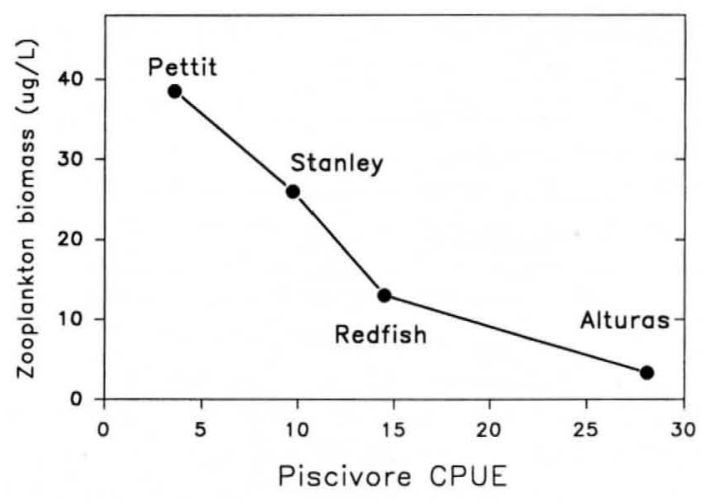

FIGURE 7.-Comparison of predation risk (CPUE = piscivore catch per overnight gill-net set in $0-20 \mathrm{~m}$ depths) and food supply ( $\mu$ g crustacean zooplankton/L, from Luecke et al. 1996) experienced by $O$. nerka in the Sawtooth Valley lakes.

growth rates over growth efficiency. With less food and higher predation risk, as in Alturas Lake, fish obtained lower rations and grew slower but more efficiently (Figure 8 ) by remaining deeper in lower temperatures to minimize metabolic costs.

\section{Discussion}

The efforts to rehabilitate the Snake River sockeye salmon stock require quantitative assessment of the distribution and abundance of sockeye salmon or kokanee and sympatric species in nursery lakes. From this assessment, researchers can interpret the behavior, dynamics, and potential for enhancement of juvenile sockeye salmon within the context of spatial-temporal changes in density of potential competitors, predators, and prey.

Sockeye salmon and kokanee were generally deep or absent from the water column during the day but dispersed into the epilimnion and metalimnion during dusk and dark hours with the smallest fish moving closest to the surface. This pattern was consistent with observations from other populations in the Pacific Northwest (Narver 1970; Woodey 1972; Eggers 1978; Clark and Levy 1988; Levy 1990; Beauchamp 1994). Daytime concentrations of other fishes in shallower waters corresponded with the presence of rainbow trout, brook trout, or cutthroat trout; shallow nocturnal concentrations corresponded with the presence of redside shiners.

Diel changes in the species composition of the limnetic community could influence our ability to accurately assess the abundance and size distribution of sockeye salmon or kokanee in these lakes, but information gained from complementary

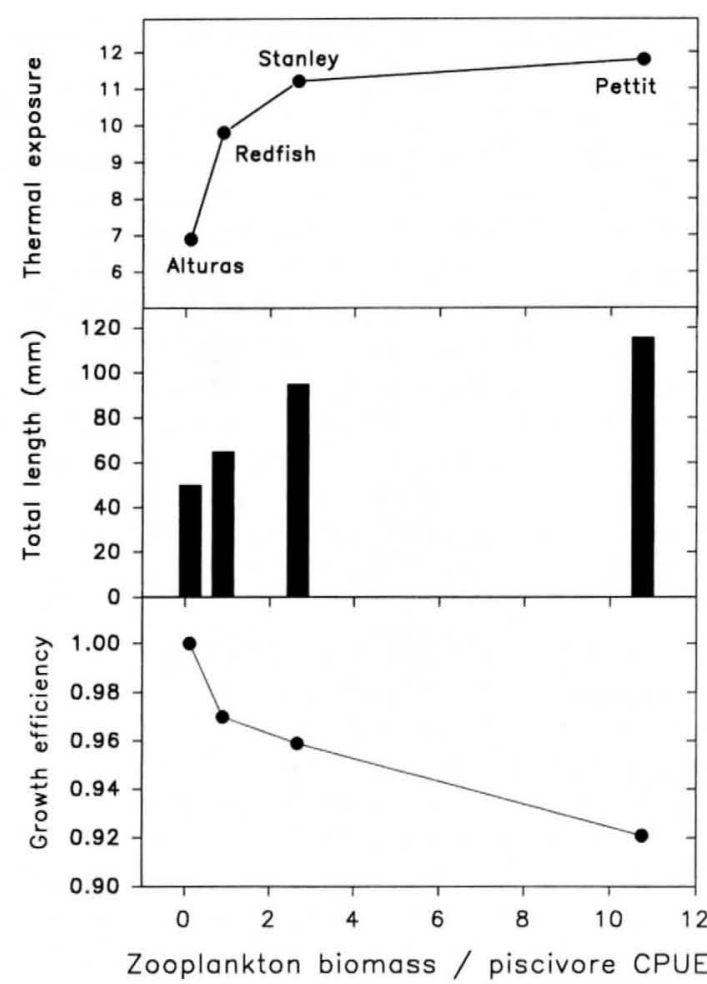

FIGURE 8.-The relations of food supply and predation risk to (top) nocturnal thermal exposure, (middle) length of age-0 O. nerka at the end of September, and (bottom) bioenergetic growth efficiency in the Sawtooth Valley lakes. Lake order (Alturas, Redfish, Stanley, Pettit; left to right) is the same for all three panels.

sampling with midwater trawls, gill nets, and hydroacoustics minimized this uncertainty. Nocturnal midwater trawling indicated that sockeye salmon or kokanee were the predominant nocturnal species in most of the study lakes. Redside shiners in Pettit Lake were an exception to this, but they were distinguishable from $O$. nerka because of differences in depth and habitat associations.

Due to their shallow distribution, large errors could result if redside shiners were not removed from the hydroacoustic abundance estimate. The volume of water sampled by the acoustic cone in shallow strata is quite small relative to deeper strata (the cross-sectional area of the cone increases as the square of distance [depth] from the transducer; Thorne 1983). Thus, large multipliers are needed to expand fish density from sample volumes to an abundance estimate for the entire volume of the shallowest stratum. Similarly, the abundance of $O$. nerka might be underestimated because the highest densities of small targets were 
often in the shallowest depth strata $(5-10 \mathrm{~m})$. Because epilimnetic temperatures did not prevent access to surface strata by salmonids, supplementary sampling (e.g., with side-looking transducers and surface trawls) in these shallow strata is recommended for future work in similar situations.

The presence of sympatric planktivorous fishes in the limnetic zone has implications for estimating the total consumption demand on the zooplankton resource by potential competitors. Our ability to correctly estimate zooplanktivorous demand in time and space depends on an accurate assessment of all the major consumers using this resource. Rainbow trout and redside shiners in particular are facultative zooplanktivores. Rainbow trout (Beauchamp 1990) and juvenile sockeye salmon tend to forage during daylight and crepuscular periods (Doble and Eggers 1978; Levy 1990), whereas redside shiners generally feed most heavily during crepuscular or nocturnal periods (Johannes and Larkin 1961; W. A. Wurtsbaugh, unpublished data). Rainbow trout can feed without light limitation in the epilimnion during daylight and crepuscular periods. If zooplankton densities were reduced such that search time was increased under low light intensities, then rations of sockeye salmon or kokanee could be reduced before the lower prey densities affected rations of rainbow trout or other surface-oriented, daylight-feeding planktivores. On moonless nights, juvenile sockeye salmon can feed on zooplankton at $5-35 \%$ of their maximum rate at depths providing $10-100 \%$ of surface light intensities (0.005-0.0005 lux; Ali 1959). This visual feeding threshold corresponds with nocturnal feeding depths from the surface to $18 \mathrm{~m}$ in Redfish Lake, $16 \mathrm{~m}$ in Alturas Lake, $14 \mathrm{~m}$ in Pettit Lake, and $8 \mathrm{~m}$ in Stanley Lake. Except for Alturas Lake (and Yellow Belly Lake, which contains no sockeye salmon), most limnetic targets in the other lakes occupied depths at or above this sight-feeding threshold at night (see Figures 3, 5, 6).

Alturas Lake contained the largest density of potential piscivores (northern squawfish and rainbow trout), and these fish were concentrated at depths above $20 \mathrm{~m}$. The deeper distribution pattern of juvenile $O$. nerka in Alturas Lake could be a response to higher predation risk in the epilimnetic waters of this lake. This deeper diel distribution has several consequences for growth: (1) limited access to higher densities of zooplankton at shallower depths; (2) confinement to lower temperatures; and (3) a higher density of limnetic planktivores concentrated in a smaller volume of water. Indeed, growth of $O$. nerka in Alturas Lake was lower than in the other Sawtooth Valley lakes (Rieman and Myers 1992; Luecke et al. 1996).

The relative influence of predation risk, foraging rates, and bioenergetic efficiency on the diel distribution of juvenile $O$. nerka are difficult to separate and have been the subject of considerable attention (Brett 1971; Eggers 1978; Clark and Levy 1988; Levy 1990). The limnetic environment is often structured by vertical gradients in food supply, light, vulnerability to predators, temperature, and dissolved oxygen, and these translate into vertical gradients of foraging opportunity, predation risk, and physiological efficiency. Juvenile $O$. nerka may form schools during daylight at intermediate depths to extend daily foraging opportunities with some protection from predators (Eggers 1978). Such schools were detected by echo integration in Redfish Lake during 1991, but no schools were found in Alturas Lake. This suggests that $O$. nerka in Alturas Lake either remained on the bottom during daylight or formed schools that were not detected during our surveys. The latter is unlikely because Alturas Lake contained the highest density of $O$. nerka of all the lakes surveyed in the basin.

Zooplankton biomass in Alturas Lake was 3.4 micrograms/L, which was only $6.7-25 \%$ of the biomass in the other lakes (Budy et al. 1994; Luecke et al. 1996), and zooplankton density was only slightly greater in $0-10 \mathrm{~m}$ than in the whole water column (P. E. Budy and C. Luecke, unpublished data). Even if zooplankton density was constant across all depths, foraging success would be reduced in deeper water; reaction distance and search volume decline because light intensity decays exponentially with depth (Eggers 1977; Aksnes and Giske 1993). By migrating to shallower waters during crepuscular hours, juveniles feed where light is sufficiently high to detect zooplankton, while exposure time and probability of detection by predators is minimized (Clark and Levy 1988). Because each lake presents a unique combination of food supply, predation risk, and thermal and optical regimes, fish should tailor their response appropriately to maximize their fitness.

We related the depth distribution of $O$. nerka to the unique combination of zooplankton availability and predator density observed in each lake and then examined the consequences of these distribution patterns in terms of thermal experience, growth, and growth efficiency. Sockeye salmon and kokanee can consume larger rations and grow faster up to temperatures of $15^{\circ} \mathrm{C}$, but if rations are limited, growth efficiency improves at lower 
temperatures (Brett et al. 1969; Brett 1971). Under favorable growth and survival conditions, $O$. nerka occupied shallower depths, experienced higher temperatures, and grew faster but less efficiently. However, with less food and higher predation risk, as in Alturas Lake, fish ate smaller rations but grew more efficiently by remaining in lower temperatures to minimize metabolic costs. Thus, each population used different strategies to maximize growth potential within the constraints of the food supply, predation risk, and thermal environment of each lake.

This assessment of the abundance and diel distribution of sockeye salmon or kokanee and sympatric limnetic species represents an important step toward quantifying the food web interactions in the Sawtooth Valley lakes and provides insight into limitations on potential future sockeye salmon production. The abundance of kokanees and other potential competitors among the Sawtooth Valley lakes represent the magnitude of food resources that are currently diverted from smolt production. Catch rates of potential predators provided a relative measure of predation risk among lakes, and the diel distribution patterns of $O$. nerka reflected the behavioral response of this species to the combination of biotic and abiotic conditions experienced in each lake. Supplied with these comparisons, managers should be better equipped to identify factors that limit production potential in each lake and prescribe customized remedies (e.g., fertilization, competitor or predator control, toxin removal). When examining the ratio of food supply to predation risk, managers must evaluate the feasibility of changing the numerator or denominator enough to effect a substantial change in the ratio. This assessment will depend on the specific characteristics of each system. For instance, a large infusion of resources would be required to improve the food supply to predator ratio in Alturas Lake, whereas larger benefits would accrue from incremental improvements in Redfish Lake. Enhancing the food supply in Alturas Lake may not be enough to improve smolt production. This may simply shift the primary limitation from food supply to predation because predators might still prevent access to the more favorable foraging and thermal conditions in epilimnetic waters. Although further development will be required, this procedure provides an initial framework for evaluating how multiple limiting factors interact to influence community dynamics and production of desirable populations.

\section{Acknowledgments}

This project was supported by the Bonneville Power Administration, the Shoshone-Bannock Tribes, the Idaho Department of Fish and Game, and the Ecology Center at Utah State University.

\section{References}

Aksnes, D. L., and J. Giske. 1993. A theoretical model of aquatic visual feeding. Ecological Modelling 67: 233-250.

Ali, M. A. 1959. The ocular structure, retinomotor and photo-behavioral responses of juvenile Pacific salmon. Canadian Journal of Zoology 37:965-996.

Beauchamp, D. A. 1990. The seasonal and diel food habits of rainbow trout stocked as juveniles in Lake Washington. Transactions of the American Fisheries Society 119:475-482.

Beauchamp, D. A. 1994. Spatial and temporal dynamics of piscivory: implications for food web stability and the transparency of Lake Washington. Lake and Reservoir Management 9:151-154.

Beauchamp, D. A., M. G. LaRiviere, and G. L. Thomas. 1995. Evaluation of competition and predation as limits to juvenile kokanee and sockeye salmon production in Lake Ozette, Washington. North American Journal of Fisheries Management 15:193-207.

Beauchamp, D. A., D. J. Stewart, and G. L. Thomas. 1989. Corroboration of a bioenergetics model for sockeye salmon. Transactions of the American Fisheries Society 118:597-607.

Bevan, D., and six coauthors. 1994. Snake River recovery team: Final recommendations to the U.S. National Marine Fisheries Service. NMFS, Portland, Oregon.

Bjornn, T. C., D. R. Craddock, and D. R. Corley. 1968. Migration and survival of Redfish Lake, Idaho, sockeye salmon, Oncorhynchus nerka. Transactions of the American Fisheries Society 97:360-373.

Brandt, S. B., D. M. Mason, and E. V. Patrick. 1992. Spatially-explicit models of fish growth rate. Fisheries $17(2): 23-31,34-35$.

Brett, J. R. 1971. Energetic responses of salmon to temperature. A study of some thermal relations in the physiology and freshwater ecology of sockeye salmon (Oncorhynchus nerka). American Zoologist 11:99-113.

Brett, J. R., J. E. Shelbourn, and C. T. Shoop. 1969. Growth rate and body composition of fingerling sockeye salmon, Oncorhynchus nerka, in relation to temperature and ration size. Journal of the Fisheries Research Board of Canada 26:2363-2394.

Budy, P., and C. Luecke. 1994. Assessment of fish growth potential using bioenergetics simulations and a field test with kokanee. Pages 100-115 in D. Teuscher and D. Taki, editors. Snake River sockeye salmon habitat and limnological research, annual report 1993. U.S. Department of Energy, Project 91-71, DE-BI79-91BP22548, Portland, Oregon.

Budy, P., C. Luecke, W. A. Wurtsbaugh, and H. P. Gross. 1994. Effects of nutrient enhancement on juvenile 
sockeye salmon growth. Lake and Reservoir Management 9:140-145.

Budy, P., C. Luecke, W. A. Wurtsbaugh, H. P. Gross, and C. Gubala. 1995. Limnology of Sawtooth Valley lakes with respect to potential growth of juvenile Snake River sockeye salmon. Northwest Science 69:133-150.

Burczynski, J. J., and R. L. Johnson. 1986. Application of dual-beam acoustic survey techniques to limnetic populations of juvenile sockeye salmon (Oncorhynchus nerka). Canadian Journal of Fisheries and Aquatic Sciences 43:1776-1788.

Burgner, R. L. 1992. Life history of sockeye salmon. Pages 1-117 in C. Groot and L. Margolis, editors. Pacific salmon life histories. University of British Columbia Press, Vancouver.

Clark, C. W., and D. A. Levy. 1988. Diel vertical migrations by juvenile sockeye salmon and the antipredation window. American Naturalist 131:271290.

Dahm, E., J. Hartman, T. Lindem, and H. Loffler. 1985. EIFAC experiments on pelagic fish stock assessment by acoustic methods in Lake Constance. EIFAC (European Inland Fisheries Advisory Commission) Occasional Paper 15.

Doble, B. D., and D. M. Eggers. 1978. Diel feeding chronology, rate of gastric evacuation, daily ration, and prey selectivity in Lake Washington sockeye salmon. Transactions of the American Fisheries Society 107:36-45.

Dwyer, W. P., and R. H. Kramer. 1975. The influence of temperature on scope for activity in cutthroat trout Salmo clarki. Transactions of the American Fisheries Society 104:552-554.

Eggers, D. M. 1977. The nature of prey selection by planktivorous fish. Ecology 58:46-59.

Eggers, D. M. 1978. Limnetic feeding behavior of juvenile sockeye salmon in Lake Washington and predator avoidance. Limnology and Oceanography 23:1114-1125.

Foerster, R. E. 1968. The sockeye salmon Oncorhynchus nerka. Fisheries Research Board of Canada Bulletin 162.

Hewett, S. W., and B. L. Johnson. 1992. Fish bioenergetics model 2: an update of a generalized bioenergetics model of fish growth for microcomputers. Sea Grant Institute, WIS-SG-92-250, Madison, Wisconsin.

Johannes, R. E., and P. A. Larkin. 1961. Competition for food between redside shiners (Richardsonius balteatus) and rainbow trout (Salmo gairdneri) in two British Columbia lakes. Journal of the Fisheries Research Board of Canada 18:203-220.
Levy, D. A. 1990. Sensory mechanism and selective advantage for diel vertical migration behavior in juvenile sockeye salmon, Oncorhynchus nerka. Canadian Journal of Fisheries and Aquatic Sciences 47:1796-1802.

Luecke, C., and W. A. Wurtsbaugh. 1993. Effects of moonlight and daylight on hydroacoustic estimates of pelagic fish abundance. Transactions of the American Fisheries Society 122:112-120.

Luecke, C., W. A. Wurtsbaugh, P. Budy, H. P. Gross, and G. Steinhart. 1996. Simulated growth and production of endangered Snake River sockeye salmon: assessing management strategies for the nursery lakes. Fisheries 21(6): 18-25.

Love, R. H. 1977. Target strength of an individual fish at any aspect. Journal of the Acoustical Society of America 62:1397-1403.

Miller, T. J., L. B. Crowder, J. A. Rice, and E. A. Marschall. 1988. Larval size and recruitment mechanisms in fishes: toward a conceptual framework. Canadian Journal of Fisheries and Aquatic Sciences 45:1657-1670.

Narver, D. 1970. Diel vertical movements and feeding of underyearling sockeye salmon and the limnetic zooplankton in Babine Lake, British Columbia. Journal of the Fisheries Research Board of Canada 9:450-491.

Parkinson, E. A., B. E. Rieman, and L. G. Rudstam. 1994. Comparison of acoustic and trawl methods for estimating density and age composition of kokanee. Transactions of the American Fisheries Society 123:841-854.

Rieman, B. E., and D. L. Myers. 1992. Influence of fish density and relative productivity on growth of kokanee in ten oligotrophic lakes and reservoirs in Idaho. Transactions of the American Fisheries Society 121:178-191.

Thorne, R. E. 1983. Hydroacoustics. Pages 239-259 in L. Nielsen and D. Johnson, editors. Fisheries techniques. American Fisheries Society, Bethesda, Maryland.

Walters, C. J., and F. Juanes. 1993. Recruitment limitation as a consequence of natural selection for use of restricted feeding habitats and predation risk-taking by juvenile fishes. Canadian Journal of Fisheries and Aquatic Sciences 50:2058-2070.

Warren, C. 1988. Sawtooth Fish Hatchery: 1986 sockeye salmon brood year report. Idaho Department of Fish and Game, Boise.

Woodey, J. C. 1972. Distribution, feeding, and growth of juvenile sockeye salmon in Lake Washington. Doctoral dissertation University of Washington, Seattle. 